\title{
Analysis of Dipylidium caninum tapeworms from dogs and cats, or their respective fleas
}

\section{Part 2. Distinct canine and feline host association with two different Dipylidium caninum genotypes}

\author{
Frédéric Beugnet $^{1, *}$, Michel Labuschagne ${ }^{2}$, Christa de Vos $^{3}$, Dionne Crafford ${ }^{3}$, and Josephus Fourie ${ }^{3}$ \\ ${ }^{1}$ Boehringer Ingelheim Animal Health, 29 Av T. Garnier, 69007 Lyon, France \\ 2 Clinomics, P.O. Box 11186, Universitas, Bloemfontein, 9321, South Africa \\ ${ }^{3}$ Clinvet, P.O. Box 11186, Universitas, Bloemfontein, 9321, South Africa
}

Received 10 January 2018, Accepted 21 April 2018, Published online 28 May 2018

\begin{abstract}
Initial investigations suggested the existence of two distinct genotypes of Dipylidium caninum from infected cat fleas (Ctenocephalides felis). One genotype was found almost always ( $>95 \%$ ) in fleas collected from, and proglottids shed by, domestic dogs. The other was found almost always ( $>95 \%)$ in fleas collected from, and proglottids shed by, domestic cats. Molecular investigations (Part 1, in this journal) confirmed the presence of two distinct genotypes. Due to the apparent host association observed, these were referred to as the "D. caninum canine genotype" and the "D. caninum feline genotype". The current article reports on an in vivo experimental infection study assessing the host-parasite interaction for each genotype. Mixed infections with the two genotypes in both dogs and cats were conducted. The specific genotyping of proglottids allowed us to assess the specific prepatent periods, prolificity, and longevity of each genotype in dogs versus cats. The possible hybridisation was also studied through molecular evaluation of the proglottids expelled by infected dogs and cats. Results demonstrate a clear distinct host interaction. The canine D. caninum genotype occurred at a higher frequency in dogs, with a shorter prepatent period and a longer lifespan; and the feline genotype occurred at a higher frequency in cats, with a shorter prepatent period and a longer lifespan. The absence of any hybrids in the mixed infections of both dogs and cats confirm the hypothesis of two distinct genotypes, suggesting the possibility of two distinct species within Dipylidium caninum.
\end{abstract}

Key words: Dipylidium caninum, Ctenocephalides felis, dogs, cats, genotypes, host association

Résumé - Analyse des ténias Dipylidium caninum des chiens et des chats, ou de leurs puces respectives. Partie 2. Association distincte des hôtes canins et félins avec deux génotypes différents de Dipylidium caninum. Des investigations initiales ont suggéré l'existence de deux génotypes distincts au sein de Dipylidium caninum issus de puces infectées (Ctenocephalides felis). Un génotype est trouvé dans plus de $95 \%$ des cas chez des puces ou des proglottis collectés sur des chiens. L'autre est trouvé dans plus de $95 \%$ des cas sur des puces collectées sur des chats ou des proglottis éliminés par les chats. Les investigations moléculaires publiées (Partie 1, dans ce journal) ont confirmé l'existence de ces deux génotypes. Du fait de l'apparent tropisme d'hôte, ces deux génotypes sont désignés comme génotype canin et génotype félin. Le présent article présente les résultats d'infestations expérimentales ayant pour objectif d'étudier l'interaction hôte-parasite pour chaque génotype. Des infestations mixtes ont été réalisées avec les deux génotypes chez des chiens et des chats. Le génotypage spécifique a permis d'étudier les périodes prépatentes, la prolificité et la longévité de chaque génotype chez chaque hôte. La possible hybridation a aussi été étudiée par évaluation moléculaire des proglottis éliminés par les chiens et les chats infestés. Les résultats ont démontré une interaction hôte-parasite bien distincte. Le génotype canin de D. caninum a une fréquence plus élevée chez les chiens, avec une période de prépatence plus courte et une durée de vie plus longue, et le génotype félin a une fréquence plus élevée chez les chats, avec une période prépatente plus courte et une durée de vie plus longue. L'absence de tout hybride dans les infections mixtes des chiens et des chats confirme l'hypothèse de deux génotypes distincts, suggérant la possibilité de deux espèces distinctes au sein de Dipylidium caninum.

\footnotetext{
*Corresponding author: frederic.beugnet@merial.com
} 


\section{Introduction}

Dipylidium caninum sensu lato is an important cestode parasite with a worldwide distribution, as is evident from surveys performed in wild canids and felids, domestic cats, domestic dogs, or concurrent surveys assessing both domestic cats and dogs $[1,3,4,6,8-11,13-19,21,25,26,28,30$, 32,34-37,40,41,43-48]. Apart from infecting both canids and felids, this cestode may also occasionally infect humans $[2,24,42]$.

The intermediate hosts for this parasite are the cat and dog fleas (Ctenocephalides felis and Ctenocephalides canis, respectively), as well as the dog and cat chewing lice, Trichodectes canis, and Felicola subrostratus, respectively [31]. Due to its worldwide distribution, and its ability to infest dogs and cats, the cat flea, C. felis, is considered to be the main intermediate host $[5,12,27,46]$. Flea larvae ingest $D$. caninum eggs, with the rate of development in the flea greatly affected by temperature $[38,39]$. When adults fleas infected with suitably developed metacestodes are ingested by the canine or feline host, the parasite establishes in the small intestine. Here it develops to an adult tapeworm, with shed proglottids visible in faeces from between 17 and 19 days after infection [22,23].

Beugnet et al. [8] investigated the occurrence of $D$. caninum in fleas from client-owned cats and dogs in Europe, using a new PCR detection assay. The results indicated that easy and regular Dipylidium sp. reinfections of both cats and dogs in European households were likely. Thus, for the first time, the spread of $D$. caninum between fleas on dogs and cats was confirmed throughout Europe. In this European survey, 2.23\% of 1969 cat fleas collected from cats were found to be infected by Dipylidium sp. larvae, compared to $5.2 \%$ of 732 cat fleas collected from dogs and $3.1 \%$ of $2828 \mathrm{dog}$ fleas collected from dogs. Preliminary analyses performed during this survey, indicated genetic differences between $D$. caninum metacestodes in fleas collected from dogs and cats, respectively. Low, in 2017, suggested the presence of two clades within D. caninum species [31]. Labuschagne et al., 2018, using the DNA extracted from the initial flea collect from dogs and cats in Europe [8], and adding new fleas collected in the United States, as well as Dipylidium proglottids from Europe, Africa, and Asia, demonstrated the existence of the two distinct genotypes [29]. The initial genetic analysis started in 2012 during an epidemiological survey assessing the infection rate of fleas by Dipylidium caninum using a new PCR probe [8]. In the recent paper, Labuschagne et al., 2018, established a correspondence between the host origin of Dipylidium-infected fleas and the genotype. They demonstrated that the genotypes are not related to geography but to hosts. The so-called feline genotype of $D$. caninum was found almost exclusively in $C$. felis collected from cats $(95.1 \%)$, whereas the so-called canine-genotype was found almost exclusively in C.felis collected from dogs $(97.3 \%)$, and was the only one observed in C. canis fleas (100\%) [29]. The authors also confirmed that the Dipylidium DNA collected by Low et al., (2017) [31], from cat fleas and cat lice collected from cats belong to the feline genotype, and that the Dipylidium caninum collected by East et al., (2013) [17], also belong to the same feline genotype [29,31]. The Dipylidium from the two genotypes are kept in dogs and cats at Clinvet, Bloemfontein, South Africa, allowing the present study.

This paper reports on an in vivo experimental infection study, designed to investigate potential host association with reference to the canine and feline D. caninum genotypes [29].

The objectives of this study were thus two-fold: firstly, to establish whether the two D. caninum genotypes show distinct host interaction, i.e. prepatent period, longevity, and rate of infection; and secondly, to establish whether the genotypes could have sexual reproduction during mixed infection in either dogs or cats.

\section{Materials and Methods \\ Ethics}

The study was approved by the Institutional Animal Care and Use Committee (IACUC). The study conformed to the principles defined and explained in the European Convention for the Protection of Vertebrate Animals used for Experimental and Other Scientific Purposes and its appendix. In addition, the authors have involved the minimum number of animals in the experimental infection study for the purpose of adequate experimental infection model validation. Animals were observed daily for general health, with physical examinations performed by a veterinarian to ensure suitability for inclusion in the study. Throughout the study, the health of the animals was monitored by veterinary personnel. No abnormal clinical signs were observed during either clinical examinations or daily health observations. As a result, none of the animals required concomitant therapy or veterinary care during the study. After termination of the animal phase, the animals received the necessary concomitant therapy (deworming based on praziquantel oral administration), after which they were returned to the Clinvet colony holding facility in order to undergo a resting period.

\section{Study design}

The study was designed as a parallel group, nonblinded, randomised, single-centre study, to determine the efficiency in infecting dogs and cats with two different $D$. caninum genotypes (Figure 1 ). The D. caninum were sourced from donor cats or dogs, and served to infect fleas. The study was based on an experimental flea infestation model previously published $[7,22]$, in combination with the newly developed PCR hydrolysis probe assay [29].

\section{Animal details}

Three dogs (group 1) and three cats (group 2), all females, were included in the study. The dogs were all beagles, 10 months of age and weighed between $10.20 \mathrm{~kg}$ and $11.60 \mathrm{~kg}$. The cats were all domestic shorthair, with ages 7,9 and 27 months respectively, and body weight ranging between $1.90 \mathrm{~kg}$ and $2.92 \mathrm{~kg}$. 


\section{A. Source of parasites}

\section{D. caninum infected cats and dogs}
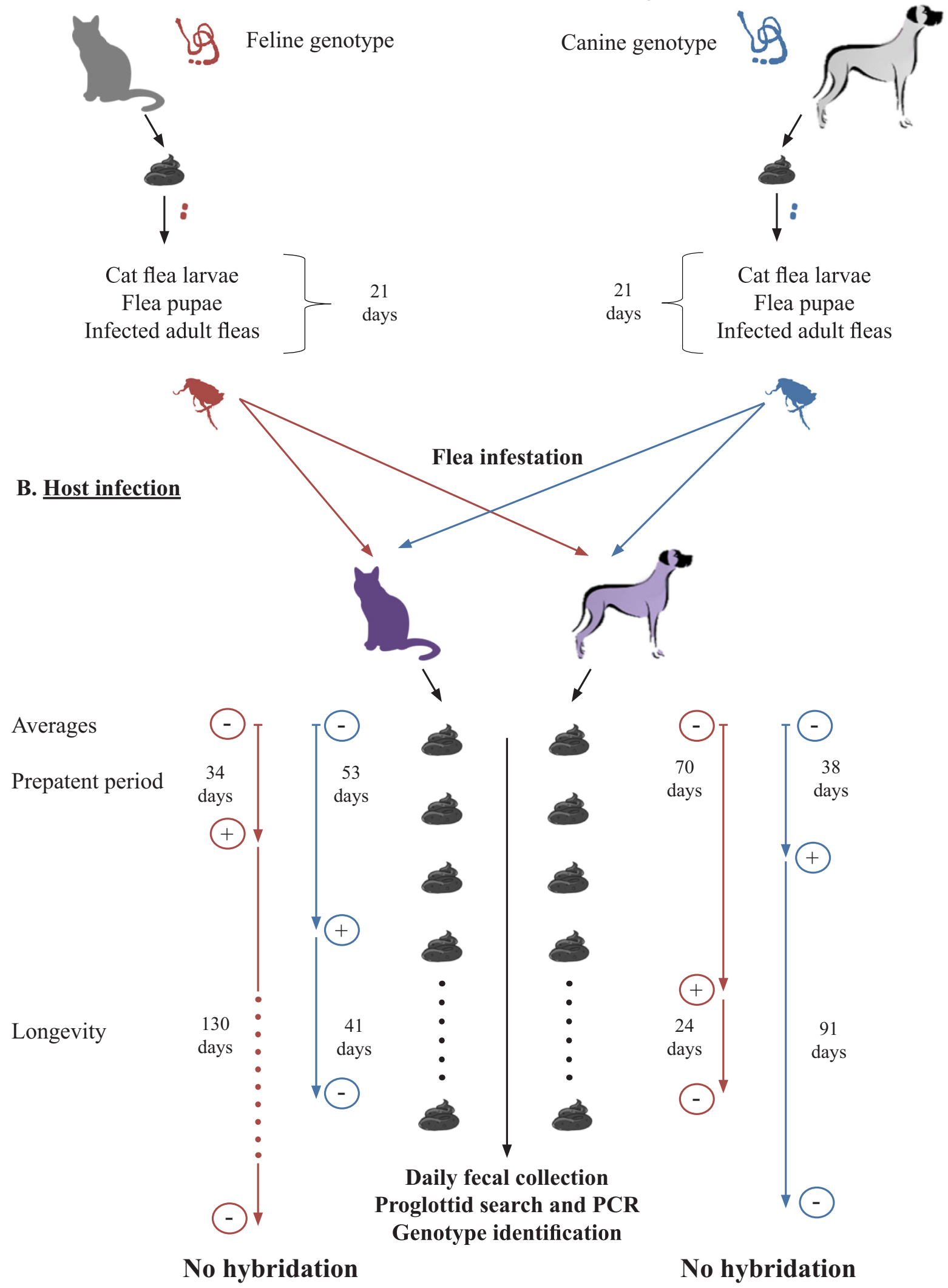

Figure 1. Graphical presentation of the experimental study on Dipylidium caninum genotypes and host association. 


\section{Experimental model overview}

Cats and dogs were infected concomitantly with both the canine and feline D. caninum genotypes, by means of skin infestation with D. caninum-infected $C$. felis fleas.

See Fourie et al. [22,23] as well as Beugnet et al. [7] for a detailed description of the experimental infection model employed.

The primary criteria for model validation was a positive result on PCR hydrolysis probe genotyping performed on faeces or positive identification of a $D$. caninum proglottid collected during macroscopic examination of cages and/or faeces [29]. While both methods constituted confirmation of D. caninum infection, PCR hydrolysis probe genotyping also constituted confirmation of the genotype and hence allowed evaluation of potential genotype host associations. PCR hydrolysis probe genotyping also allowed observation of hybrid DNA patterns. A secondary criterion considered was the duration of proglottid shedding.

\section{Flea infestations and related actions}

A first step was to breed two batches of fleas, from eggs to pupae, during approximately 21 days on a flea-rearing medium containing Dipylidium proglottids originating from infected donor cats and dogs with their respective Dipylidium genotype.

A second step before flea infestation of dogs and cats was to perform PCR hydrolysis probe genotyping analyses on the newly emerged fleas to confirm their infection by D. caninum larvae (as well as the D. caninum genotype).

In addition, a sample of 30 fleas from each batch used was dissected and examined microscopically to determine the prevalence of infection with $D$. caninum metacestodes, as well as their level of development. With reference to the latter, some organisation of the hooklets had to be evident in at least one of the metacestodes present.

Fleas were killed by freezing them, after which they were dissected with the aid of a dissection microscope using two needles. One needle was used to pin the flea down by the thorax, and the other to cut open the tip of the abdomen. Contents were squeezed out using the needle. Metacestodes, if present, were counted and stage of development noted.

The third step consisted in the infestation of dogs and cats with live fleas from the two batches. As fleas containing respective feline and canine genotypes were placed on the animals, it was necessary to have batches with similar Dipylidium sp. infection rates for each infestation.

Thus, after establishing metacestode infection rates, the batches were "diluted" by addition of fleas from a laboratory $C$. felis flea strain known not to be infected with D. caninum, in order to achieve infection rates that were similar between the two Dipylidium infected flea batches.

Flea infestations were performed on Days 0, 13 and 28. Each cat/dog was skin infested with 200 fleas, including 100 infected fleas ( 50 with each $D$. caninum genotype). Animals were allowed to groom freely. Dogs and cats were housed individually during the 168 days of the animal phase.
Table 1. Definition of "weeks" (as used in statistical analyses) according to study day periods.

\begin{tabular}{lc}
\hline Study day period & Week \\
\hline 19 to 23 & 1 \\
26 to 30 & 2 \\
33 to 37 & 3 \\
40 to 44 & 4 \\
47 to 51 & 5 \\
54 to 58 & 6 \\
61 to 65 & 7 \\
68 to 72 & 8 \\
75 to 79 & 9 \\
82 to 86 & 10 \\
89 to 93 & 11 \\
96 to 100 & 12 \\
103 to 107 & 13 \\
110 to 114 & 14 \\
117 to 121 & 15 \\
124 to 128 & 16 \\
131 to 135 & 17 \\
138 to 142 & 18 \\
145 to 149 & to 156 \\
159 to 163 & 19 \\
166 to 168 & 19 \\
\hline & 21 \\
\hline & 22 \\
\hline
\end{tabular}

At Day 56, in order to kill fleas, each animal was treated with an ectoparasiticide (Frontline Plus ${ }^{\circledR}$ for cats and NexGard ${ }^{\circledR}$ for dogs), according to label instructions.

\section{Proglottid collection and analyses}

Macroscopic examination of faeces and the individual cages for shed proglottidswas performed at least twice weekly from Days 21 (estimated end of pre-patent period following first flea infestation on Day 0) to Day 168. Collected proglottids were subjected to DNA isolation using a commercial kit. Isolated DNA was subjected to specific PCR amplification of the $28 \mathrm{~S} \mathrm{rDNA}$ region as described by Beugnet et al. [8], followed by genotyping using hydrolysis probes specific for each genotype [29].

PCR hydrolysis probe-based genotyping was used to discriminate between the two identified genotypes exhibiting specific associations towards dogs and cats.

All proglottids were also screened for hybridization using a hybridization probe-based DNA genotyping qPCR assay [29].

\section{Statistical analysis}

Seven day periods were used to define "weeks", as was employed in statistical analyses (Table 1). Weeks were defined by the Investigator based on the pre-patent period of D. caninum, and hence the anticipated commencement of proglottid shedding. 
Table 2. Summary of metacestode infection rates of the fleas used, prior to each infestation.

\begin{tabular}{|c|c|c|c|c|}
\hline \multirow{2}{*}{$\begin{array}{l}\text { Infestation } \\
\text { Day }\end{array}$} & \multicolumn{2}{|c|}{ Metacestode infection in the original flea batches (\%) } & \multirow[t]{2}{*}{ Age of the flea batches } & \multirow[t]{2}{*}{ Comments } \\
\hline & Feline genotype & Canine genotype & & \\
\hline 0 & 40 & 33.3 & 13 days & $\begin{array}{l}\text { Feline genotype diluted to } \\
33.3 \% \text { infection rate by } \\
\text { adding uninfected fleas }\end{array}$ \\
\hline 13 & 13.3 & 56.7 & 20 days & $\begin{array}{l}\text { Canine genotype diluted to } \\
13.3 \% \text { infection rate }\end{array}$ \\
\hline 28 & 10 & 60 & $\begin{array}{l}20 \text { days for the canine } \\
\text { genotype } \\
21 \text { days for the feline } \\
\text { genotype }\end{array}$ & $\begin{array}{l}\text { Canine genotype diluted to } \\
10 \% \text { infection rate }\end{array}$ \\
\hline
\end{tabular}

The validity of the experimental model was confirmed based on the positive identification of D. caninum proglottids in faeces.

The success of infection by the $D$. caninum genotypes was measured by the number of dogs/cats being infected by each genotype, respectively.

For real-time PCR results, canine and feline genotypes were presented descriptively for each three-week interval and overall period. Differences between these genotypes for each interval were compared using a Chi-square test. The level of significance of the formal tests was set at $5 \%$ and all tests were two-sided.

The pre-patent period was defined as the number of days from first flea infestation (Day 0) to the first PCRpositive test in proglottids collected from faeces.

The duration of infestation for each D. caninum genotype (worm longevity) was defined as the total number of days where the infestation was regarded as successful, as confirmed by the presence of D. caninum proglottids in faeces and their identification by PCR.

The rate of success, the pre-patent period and the duration of infestation were presented descriptively for cats and dogs, for both the feline and canine D. caninum genotypes respectively, at each assessment time point.

The rate of success was presented using frequencies and percentages, while the duration of the pre-patent period and the duration of infestation were presented using summary statistics (mean, standard deviation, median, minimum and maximum).

SAS Version 9.3 TS Level 1M2 was used for all the statistical analyses.

With reference to sample size, three dogs and three cats were used in this study, which was considered adequate for experimental model method validation using different genotypes. The statistical unit was the individual animal.

\section{Efficiency of the in vivo experimental model}

The model was regarded as effective if host animals challenged with fleas infected with both feline and canine genotypes of $D$. caninum became infected, as confirmed by expulsion of proglottids and verified by PCR, with either or both genotypes.

\section{Results}

\section{Metacestode infection rates}

The metacestode infection rates in flea batches placed on animals (obtained through batch dilution with uninfected fleas as described previously), are tabulated in Table 2. Actual metacestode infection rates in the flea batches employed for host infestations ranged between $10 \%$ and $33.3 \%$.

\section{Infection success rates}

The rates of $D$. caninum infection success are presented descriptively for cats and dogs, for both the feline and canine $D$. caninum genotypes respectively, at each assessment time point, in Table 3.

\section{Dipylidium sp. infection in dogs}

Infections with the canine $D$. caninum genotype were first observed in all three dogs from Week 5 to 7 , with observed infections persisting throughout the study period, while infection with the feline genotype was not observed in all three dogs during that period. Infection with the feline genotype in dogs was observed in 2 out of 3 dogs positive from Week 2 to 4 , and then again from Week 17 to 19 . However, considering the total period, the three dogs did become infected with the feline strain.

\section{Dipylidium infection in cats}

Infections with the feline genotype were first observed in all three cats from Week 2 to 4, with observed infections persisting throughout the study period, while infection with the canine genotype was not observed in all cats during that period. Infections with the canine genotype were first observed in all three cats in group 2 from Week 8 to 10 , and then again from Week 17 to 22 .

\section{Genotyping results}

Hydrolysis probe-based genotyping results are presented in Table 4a (dog group) and Table 4b (cat group). 
Table 3. Rate of Dipylidium caninum infection success (positive animals based on presence of proglottids and positive RLFP results) expressed as frequencies and percentages for the time periods assessed.

\begin{tabular}{|c|c|c|c|}
\hline \multirow[t]{2}{*}{ Type } & \multirow[t]{2}{*}{ Weekly interval } & \multirow{2}{*}{$\begin{array}{l}\begin{array}{l}\text { Group } 1 \\
(\text { dogs })\end{array} \\
\text { Rate }\end{array}$} & \multirow{2}{*}{$\begin{array}{l}\text { Group } 2 \\
\text { (cats) } \\
\text { Rate }\end{array}$} \\
\hline & & & \\
\hline \multirow{8}{*}{ Canine genotype } & Week 2 to 4 & $2 / 3(66 \%)$ & $1 / 3(33 \%)$ \\
\hline & Week 5 to 7 & $3 / 3(100 \%)$ & $2 / 3(66 \%)$ \\
\hline & Week 8 to 10 & $2 / 3(66 \%)$ & $3 / 3(100 \%)$ \\
\hline & Week 11 to 13 & $3 / 3(100 \%)$ & $2 / 3(66 \%)$ \\
\hline & Week 14 to 16 & $3 / 3(100 \%)$ & $2 / 3(66 \%)$ \\
\hline & Week 17 to 19 & $1 / 3(33 \%)$ & $3 / 3(100 \%)$ \\
\hline & Week 20 to 22 & $2 / 3(66 \%)$ & $3 / 3(100 \%)$ \\
\hline & Total (Week 2 to 22 ) & $3 / 3(100 \%)$ & $3 / 3(100 \%)$ \\
\hline \multirow{8}{*}{ Feline genotype } & Week 2 to 4 & $2 / 3(66 \%)$ & $3 / 3(100 \%)$ \\
\hline & Week 5 to 7 & $1 / 3(33 \%)$ & $3 / 3(100 \%)$ \\
\hline & Week 8 to 10 & $1 / 3(33 \%)$ & $3 / 3(100 \%)$ \\
\hline & Week 11 to 13 & - & $3 / 3(100 \%)$ \\
\hline & Week 14 to 16 & - & $3 / 3(100 \%)$ \\
\hline & Week 17 to 19 & $2 / 3(66 \%)$ & $3 / 3(100 \%)$ \\
\hline & Week 20 to 22 & $1 / 3(33 \%)$ & $3 / 3(100 \%)$ \\
\hline & Total (Week 2 to 22) & $3 / 3(100 \%)$ & $3 / 3(100 \%)$ \\
\hline
\end{tabular}

Group 1: Dogs were infected with the canine and feline D. caninum genotypes by means of topical infestation of infected $C$. felis fleas. Group 2: Cats were infected with the canine and feline D. caninum genotypes by means of topical infestation of infected $C$. felis fleas.

Table 4a. Hydrolysis probe-based genotyping result frequency counts (Dipylidium caninum feline and canine genotypes) in dogs (group 1).

\begin{tabular}{|c|c|c|c|}
\hline \multirow[t]{2}{*}{ Time point } & \multicolumn{2}{|c|}{ Dipylidium caninum genotype } & \multirow{2}{*}{$\begin{array}{l}\text { Failed reaction } \\
\mathrm{n} / \mathrm{N}(\%)\end{array}$} \\
\hline & $\begin{array}{l}\text { Canine } \\
\mathrm{n} / \mathrm{N}(\%)\end{array}$ & $\begin{array}{l}\text { Feline } \\
\mathrm{n} / \mathrm{N}(\%)\end{array}$ & \\
\hline Week 2 to 4 & $121 / 146(82.9)$ & $8 / 146(5.5)$ & $17 / 146(11.6)$ \\
\hline Week 5 to 7 & $214 / 332(64.5)$ & $102 / 332(30.7)$ & $16 / 332(4.8)$ \\
\hline Week 8 to 10 & $48 / 49(98.0)$ & $1 / 49(2.0)$ & \\
\hline Week 11 to 13 & $23 / 27(85.2)$ & - & $4 / 27(14.8)$ \\
\hline Week 14 to 16 & $11 / 14(78.6)$ & - & $3 / 14(21.4)$ \\
\hline Week 17 to 19 & $2 / 31(6.5)$ & $3 / 31(9.7)$ & $26 / 31(83.9)$ \\
\hline Week 20 to 22 & $13 / 17(76.5)$ & $1 / 17(5.9)$ & $3 / 17(17.6)$ \\
\hline Total (Week 2 to 22 ) & $432 / 616(70.1)$ & $115 / 616(18.7)$ & $69 / 616(11.2)$ \\
\hline
\end{tabular}

Group 1: Dogs were infected with the canine and feline D. caninum genotypes by means of topical infestation with infected $C$. felis fleas.

Table 4b. Hydrolysis probe-based genotyping result frequency counts (Dipylidium caninum feline and canine genotypes) for cats (group 2).

\begin{tabular}{|c|c|c|c|}
\hline \multirow[t]{2}{*}{ Time point } & \multicolumn{2}{|c|}{ Dipylidium caninum genotype } & \multirow{2}{*}{$\begin{array}{l}\text { Failed reaction } \\
\mathrm{n} / \mathrm{N}(\%)\end{array}$} \\
\hline & $\begin{array}{l}\text { Canine } \\
\mathrm{n} / \mathrm{N}(\%)\end{array}$ & $\begin{array}{l}\text { Feline } \\
\mathrm{n} / \mathrm{N}(\%)\end{array}$ & \\
\hline Week 2 to 4 & $1 / 71(1.4)$ & $65 / 71(91.5)$ & $5 / 71(7.0)$ \\
\hline Week 5 to 7 & $7 / 168(4.2)$ & $152 / 168(90.5)$ & $9 / 168(5.4)$ \\
\hline Week 8 to 10 & $14 / 157(8.9)$ & $131 / 157(83.4)$ & $12 / 157(7.6)$ \\
\hline Week 11 to 13 & $7 / 199(3.5)$ & $154 / 199(77.4)$ & $38 / 199(19.1)$ \\
\hline Week 14 to 16 & $4 / 228(1.8)$ & $171 / 228(75.0)$ & $53 / 228(23.2)$ \\
\hline Week 17 to 19 & $35 / 526(6.7)$ & $450 / 526(85.6)$ & $41 / 526(7.8)$ \\
\hline Week 20 to 22 & $27 / 387(7.0)$ & $349 / 387(90.2)$ & $11 / 387(2.8)$ \\
\hline Total (Week 2 to 22 ) & $95 / 1736(5.5)$ & $1472 / 1736(84.8)$ & $169 / 1736(9.7)$ \\
\hline
\end{tabular}

Group 2: Cats were infected with the canine and feline D. caninum genotypes by means of topical infestation with infected $C$. felis fleas. 
Table 5. Statistical comparison of the cat and dog groups in terms of $D$. caninum genotypes.

\begin{tabular}{|c|c|c|c|}
\hline Comparison & Type & Time point & $p$-value \\
\hline \multirow{16}{*}{$\begin{array}{l}\text { Group } 1 \\
\text { with } \\
\text { group } 2\end{array}$} & \multirow{9}{*}{$\begin{array}{l}\text { Canine } \\
\text { genotype }\end{array}$} & Week 2 to 4 & $<0.0001$ \\
\hline & & Week 5 to 7 & $<0.0001$ \\
\hline & & Week 8 to 10 & $<0.0001$ \\
\hline & & Week 11 to 13 & $<0.0001$ \\
\hline & & Week 14 to 16 & $<0.0001$ \\
\hline & & Week 17 to 19 & 0.9649 \\
\hline & & Week 20 to 22 & $<0.0001$ \\
\hline & & Total (Week 2 to 22) & $<0.0001$ \\
\hline & & Week 2 to 4 & $<0.0001$ \\
\hline & \multirow{7}{*}{$\begin{array}{c}\text { Feline } \\
\text { genotype }\end{array}$} & Week 5 to 7 & $<0.0001$ \\
\hline & & Week 8 to 10 & $<0.0001$ \\
\hline & & Week 11 to 13 & $<0.0001$ \\
\hline & & Week 14 to 16 & $<0.0001$ \\
\hline & & Week 17 to 19 & $<0.0001$ \\
\hline & & Week 20 to 22 & $<0.0001$ \\
\hline & & Total (Week 2 to 22 ) & $<0.0001$ \\
\hline
\end{tabular}

$p$-value: Chi-square test

Group 1: Dogs were infected with the canine and feline $D$. caninum genotypes by means of topical infestation with infected C. felis fleas.

Group 2: Cats were infected with the canine and feline $D$. caninum strains by means of topical infestation with infected $C$. felis fleas.

These results confirmed that the canine genotype had a higher frequency of occurrence in dogs, while the feline genotype had a higher frequency of occurrence in cats.

Results ( $p$-values) after statistically comparing the genotyping results for the two groups (Chi-square analysis), with reference to $D$. caninum genotype employed (either canine or feline), are presented in Table 5 .

With the exception of Week 17 to 19, dogs and cats differed significantly with regard to the feline and canine D. caninum genotype frequency of occurrence.

\section{Durations of pre-patent period}

Durations of the pre-patent period are presented in Table 6a (dog group) and Table 6b (cat group), using summary statistics (mean, standard deviation, median, minimum and maximum). In dogs, the average pre-patent period was shorter for the canine genotype (i.e. 38 days) compared to the feline genotype (70 days), while the opposite was true in cats (34 days for feline genotype versus 53 days for canine genotype). With 3 animals in each group, these differences were not significant.

\section{Durations of infestation}

Durations of infestation are presented descriptively for cats and dogs, for both the feline and canine $D$. caninum genotypes, respectively in Table 7a (group 1) and Table $7 \mathrm{~b}$ (group 2). In dogs, the observed infection
Table 6a. Individual and summary statistics of pre-patent periods (in days) for dogs (group 1).

\begin{tabular}{llc}
\hline $\begin{array}{l}\text { Animal ID } \\
\text { Statistics }\end{array}$ & Canine strain & Feline strain \\
\hline 5A8 8F3 & 26 & 29 \\
5 A9 67F & 27 & 30 \\
697 FFA & 61 & 152 \\
& & \\
$\mathrm{n}$ & 3 & 3 \\
Mean & 38.0 & 70.3 \\
SD & 19.92 & 70.73 \\
CV \% & 52.4 & 100.6 \\
GeoMean & 35.1 & 51.2 \\
Median & 27.0 & 30.0 \\
Minimum & 26 & 29 \\
Maximum & 61 & 152 \\
\hline
\end{tabular}

$* p=0.4884$ (no significant difference between canine and feline genotypes)

The prepatent period is defined as the number of days from first flea infestation to the first PCR + test in faeces.

Group 1: Dogs were infected with the canine and feline D. caninum genotypes by means of topical infestation of infected $C$. felis fleas.

Table 6b. Individual and summary statistics of pre-patent periods (in days) for cats (group 2).

\begin{tabular}{lll}
\hline $\begin{array}{l}\text { Animal ID } \\
\text { Statistics }\end{array}$ & Canine strain & Feline strain \\
\hline 5A2 F40 & 35 & 40 \\
5CA 06E & 70 & 27 \\
869 F1E & 54 & 35 \\
& & \\
$\mathrm{n}$ & 3 & 3 \\
Mean & 53.0 & 34.0 \\
SD & 17.52 & 6.56 \\
CV \% & 33.1 & 19.3 \\
GeoMean & 51.0 & 33.6 \\
Median & 54.0 & 35.0 \\
Minimum & 35 & 27 \\
Maximum & 70 & 40 \\
\hline
\end{tabular}

with the canine genotype persisted longer compared to the feline genotype (91 days versus 24 days), while the opposite was true for cats (130 days for the feline genotype compared to 41 days for the canine one). These differences were significant.

\section{Hybridization}

No sign of hybridization between D. caninum genotypes was detected for any of the proglottid specimen samples analyzed. This demonstrates that no hybrid proglottid-containing eggs were observed, despite the six mixed infections (three in dogs, three in cats) allowing potential sexual reproduction between adult Dipylidium sp. in the intestine. 
Table 7a. Individual and summary statistics of duration of Dipylidium infection (in days) for dogs (group 1).

\begin{tabular}{lcc}
\hline $\begin{array}{l}\text { Animal ID } \\
\text { Statistics }\end{array}$ & Canine strain & Feline strain \\
\hline 5A8 8F3 & 102 & 38 \\
5A9 67F & 115 & 33 \\
697 FFA & 58 & 1 \\
n & 3 & \\
Mean & 91.7 & 3 \\
SD & 29.87 & 24.0 \\
CV \% & 32.6 & 20.07 \\
GeoMean & 88.0 & 83.6 \\
Median & 102.0 & 12.8 \\
Minimum & 58 & 33.0 \\
Maximum & 115 & 1 \\
\hline
\end{tabular}

$p=0.0312$ (significant difference between canine and feline genotypes)

The duration of infestation is defined as the total number of days where the infestation was regarded as successful as confirmed by RLFP results.

Group 1: Dogs were infected with the canine and feline D. caninum genotypes by means of infestation with infected C. felis fleas.

Table $\mathbf{7 b}$. Individual and summary statistics of duration of Dipylidium sp. infection (in days) for cats (group 2).

\begin{tabular}{llc}
\hline $\begin{array}{l}\text { Animal ID } \\
\text { Statistics }\end{array}$ & Canine strain & Feline strain \\
\hline 5 A2 F40 & 55 & 123 \\
5 CA 06E & 26 & 136 \\
869 F1E & 43 & 132 \\
& & \\
n & 3 & 3 \\
Mean & 41.3 & 130.3 \\
SD & 14.57 & 6.66 \\
CV \% & 35.3 & 5.1 \\
GeoMean & 39.5 & 130.2 \\
Median & 43.0 & 132.0 \\
Minimum & 26 & 123 \\
Maximum & 55 & 136 \\
\hline
\end{tabular}

$\overline{p=0.0007 \text { (significant difference between canine and feline }}$ genotypes)

The duration of infestation is defined as the total number of days where the infestation was regarded as successful as confirmed by RLFP results.

Group 2: Cats were infected with the canine and feline D. caninum genotypes by means of infestation with infected C. felis fleas.

\section{Discussion}

The experimental infection model based on infected flea challenges has previously been used with great success in several efficacy studies $[7,22,23]$. The molecular characterization of D. caninum isolates collected from dogs, cats, and in infected fleas collected either from dogs or cats enabled the identification of two distinct genotypes that clearly differ from each other [29]. Previous studies had also suggested the existence of different genetic profiles, or suggested that there could be clades or even different species under the name Dipylidium caninum [31].

East et al., 2013, collected Dipylidium caninum proglottids from six spotted hyena [17]. They used one of these samples to obtain 12S rRNA fragments (314 bp and $1176 \mathrm{bp}$ ). When comparing their $314 \mathrm{bp}$ sequence data with two published $D$. caninum sequences of the same fragment, they obtained a high (99\%) similarity to one sequence from Europe (accession number L49460.1) but a considerably lower similarity $(89 \%)$ to one sequence from Asia (accession number AB031362.1). When they compared the available $1176 \mathrm{bp}$ sequence (accession number KF202097) to their similar fragment from D. caninum, they obtained a relatively low similarity (89\%). By looking at their sequences and comparison to the complete mitochondrial (mt) sequences of the D. caninum feline genotype (MG587892), Labuschagne et al., obtained $99.1 \%$ identity between the $D$. caninum isolated from the hyena (KF202097) and the D. caninum feline genotype (MG567892) isolated from a cat [29]. When comparing to the mt genome of the Dipylidium dog genotype, there was only around $88.5 \%$ identity [29]. More recently, Low et al., (2017) [31], collected ectoparasites from dogs and cats in Malaysia. In this study, Ctenocephalides felis (92 specimens) and Felicola subrostratus (30 specimens) were collected from 20 cats. PCR amplification utilizing the primers published in 2014 [8] was performed for the $28 \mathrm{~S}$ rRNA gene region of Dipylidium. Low et al. also characterized the positive samples with a $12 \mathrm{~S}$ rRNA gene amplification [31]. They found that the representative 28S rRNA sequence isolated from their flea and louse specimens (GenBank accession no. KY751956) demonstrated $95 \%$ sequence similarity with that of D. caninum (GenBank accession no. AF023120), and they suggested the existence of two distinct clades within Dipylidium caninum. They concluded that their $12 \mathrm{~S}$ rRNA sequences (GenBank accession no. KY751955) were identical to the spotted hyena isolate from East et al. (GenBank accession no. KF202097) [31]. Labuschagne et al. compared the $12 \mathrm{~S}$ mt rDNA sequence of the feline and canine genotypes to the D. caninum $12 \mathrm{~S}$ mt rDNA sequences used by Low et al. [29]. The Dipylidium DNA isolates collected from cat fleas and cat louse from cats in Malaysia were identical to the $D$. caninum feline genotype [29]. The hypothesis drawn by Low et al. [31] on the existence of two clades is thus confirmed by the work of Labuschagne et al., the proposed clades corresponding to the canine and feline Dipylidium genotypes [29].

These two genotypes are not related to geographical origin, as they were found on all continents (i.e. North America, Europe, Asia, and Africa), but clearly to their host origin, dogs or cats (and hyena). Nevertheless, the specificity is not absolute, as we were able to infect cats and dogs with both genotypes during the present 
experimental study. Labuschagne et al., studying the fleas collected in 2012 [8], indicated that around $10 \%$ of the cat fleas collected on cats and $2 \%$ of the cat fleas collected on dogs, were infected with the other genotype than the host-genotype. The common presence of both cats and dogs in the same households, being infested by the same flea species (i.e. Ctenocephalides felis), could explain the infection of cats and dogs by both genotypes, but the different observed prevalences suggested biological adaptation, hence the decision to conduct the present study. On the other hand, C. canis and P. irritans fleas being more specific to dogs, $100 \%$ of the infected fleas were found to harbour the canine genotype of Dipylidium caninum [29].

The results obtained during the experimental infections demonstrated significant biological variations between the two genotypes in regard to their host association. The pre-patent periods were significantly shorter for the canine genotype in dogs and the feline genotype in cats, respectively. The duration of proglottid shedding (i.e. patent period or longevity) was significantly longer for the canine genotype in dogs and the feline genotype in cats, thus confirming biological variations and the host specificity for each genotype. The canine $D$. caninum genotype occurred at a significantly higher frequency in dogs, and the feline genotype at a significantly higher frequency in cats. Nevertheless, the host tropism was not absolute as both canine and feline genotypes were diagnosed in cats and dogs, respectively.

Even though Cyclophyllidea cestodes are hermaphrodites and present auto-fertilization, cross-fertilization is described in the presence of several adults at the same place [20,33]. Under our experimental conditions, despite mixed infections, no hybrid DNA was observed in single proglottids, demonstrating the absence of hybrid eggs.

Genomic and mitochondrial sequencing, combined with an in vivo experimental study and novel PCR hydrolysis probe genotyping assay, demonstrated that the two distinct $D$. caninum genotypes [29] present significant biological differences with a specific host association. A species is classically defined by individuals being able to reproduce together. The absence of hybrid eggs raises the question of the species level of each Dipylidium caninum genotype. Dipylidium caninum Linnaeus 1758 has originally been described in dogs. Another study is planned to assess the possible presence of morphological differences in addition to the genetic and biological observations. The current results, on both the genetic and the biological aspects, raise the question of the possible existence of two host-associated species inside the genus Dipylidium.

Acknowledgements. The authors would like to thank the research personnel from both Clinomics and Clinvet International (Pty) Ltd for their assistance in the conduct of the research. The study was funded by Merial SAS, France.

\section{Conflicts of interest}

The authors declare that they have no conflicts of interest in relation to this article.

\section{References}

1. Abdybekova AM, Torgerson PR. 2012. Frequency distributions of helminths of wolves in Kazakhstan. Veterinary Parasitology, 184, 348-351.

2. Adam AA, Saeed OM, Ibrahim HM, El HY, Ahmed ME. 2012. Case report. Dipylidium caninum infection in a 41-yearold Sudanese man in Nyala, Sudan: The first reported case in Sudan in 2006. Al Neelain Medical Journal, 2(6), 37-42.

3. Al-Sabi MNS, Chriél M, Jensen TH, Enemark HL. 2013. Endoparasites of the raccoon dog (Nyctereutes procyonoides) and the red fox (Vulpes vulpes) in Denmark 20092012-A comparative study. International Journal for Parasitology: Parasites and Wildlife, 2, 144-151.

4. Anene BM, Nnaji TO, Chime AB. 1996. Intestinal parasitic infections of dogs in the Nsukka area of Enugu State, Nigeria. Preventive Veterinary Medicine, 27, 89-94.

5. Beck W, Boch K, Mackensen H, Wiegand B, Pfister K. 2006. Qualitative and quantitative observations on the flea population dynamics of dogs and cats in several areas of Germany. Veterinary Parasitology, 137, 130-136.

6. Beiromvand M, Akhlaghi L, Fattahi Massom SH, Meamar AR, Motevalian A, Oormazdi H, Razmjou E. 2013. Prevalence of zoonotic intestinal parasites in domestic and stray dogs in a rural area of Iran. Preventive Veterinary Medicine, 109, 162-167.

7. Beugnet F, Delport P, Luus H., Crafford D, Fourie J. 2013. Preventive efficacy of Frontline ${ }^{\circledR}$ Combo and Certifect ${ }^{\circledR}$ against Dipylidium caninum infestation of cats and dogs using a natural flea (Ctenocephalides felis). Parasite, 20, 7.

8. Beugnet F, Labuschagne M, Fourie J, Jacques G, Farkas R, Cozma V., Halos L, Hellmann K, Knaus M, Rehbein S. 2014. Occurrence of Dipylidium caninum in fleas from clientowned cats and dogs in Europe using a new PCR detection assay. Veterinary Parasitology, 205, 300-306.

9. Bwalya EC, Nalubamba KS, Hankanga C, Namangala B. 2011. Prevalence of canine gastrointestinal helminths in urban Lusaka and rural Katete Districts of Zambia. Preventive Veterinary Medicine, 100, 252-255.

10. Cabrera PA, Parietti S, Haran G, Benavidez U, Lloyd S, Perera G, Valledor S, Gemmell MA, Botto T. 1996. Rates of reinfection with Echinococcus granulosus, Taenia hydatigena, Taenia ovis and other cestodes in a rural dog population in Uruguay. International Journal for Parasitology, 26, 79-83.

11. Calvete C, Lucientes J, Castillo JA, Estrada R, Gracia MJ, Peribáñez MA, Ferrer M. 1998. Gastrointestinal helminth parasites in stray cats from the mid-Ebro Valley, Spain. Veterinary Parasitology, 75, 235-240.

12. Chandra S, Forsyth M, Lawrence AL, Emery D, Šlapeta J. 2017. Cat fleas (Ctenocephalides felis) from cats and dogs in New Zealand: Molecular characterisation, presence of Rickettsia felis and Bartonella clarridgeiae and comparison with Australia. Veterinary Parasitology, 234, 25-30.

13. Dai RS, Li ZY, Li F, Liu DX, Liu W, Liu GH, He SW, Tan MY Lin RQ, Liu Y, Zhu XQ. 2009. Severe infection of adult dogs with helminths in Hunan Province, China poses significant public health concerns. Veterinary Parasitology, 160, 348-350. 
14. Dalimi A, Sattari A, Motamedi G. 2006. A study on intestinal helminthes of dogs, foxes and jackals in the western part of Iran. Veterinary Parasitology, 142, 129133.

15. Dubná S, Langrová I, Nápravník J, Jankovská I, Vadlejch J, Pekár S, Fechtner J. 2007. The prevalence of intestinal parasites in dogs from Prague, rural areas, and shelters of the Czech Republic. Veterinary Parasitology 145, 120-128.

16. Dybing NA, Fleming PA, Adams PJ. 2013. Environmental conditions predict helminth prevalence in red foxes in Western Australia. International Journal for Parasitology: Parasites and Wildlife, 2, 165-172.

17. East ML, Kurze C, Wilhelm K, Benhaiem S, Hofer H. 2013. Factors influencing Dipylidium sp. infection in a freeranging social carnivore, the spotted hyaena (Crocuta crocuta). International Journal for Parasitology: Parasites and Wildlife, 2, 257-265.

18. Eguía-Aguilar P, Cruz-Reyes A, Martínez-Maya JJ. 2005. Ecological analysis and description of the intestinal helminths present in dogs in Mexico City. Veterinary Parasitology, 127, 139-146.

19. El-Seify MA, Aggour MG, Sultan K, Marey NM. 2017. Gastrointestinal helminths of stray cats in Alexandria, Egypt: A fecal examination survey study. Veterinary Parasitology: Regional Studies and Reports, 8, 104-106.

20. Euzéby J. 1966. Cycles évolutifs, Copulation et Fécondation, in Les maladies vermineuses des animaux domestiques et leur incidence sur la pathologie humaine. Tome II Maladies dues aux plathelminthes. Fascicule premier Cestodes, Vigot Frères, Editor. Vigot Frères : Paris, France. p. 39-40.

21. Fontanarrosa MF, Vezzani D, Basabe J, Eiras DF. 2006. An epidemiological study of gastrointestinal parasites of dogs from Southern Greater Buenos Aires (Argentina): Age, gender, breed, mixed infections, and seasonal and spatial patterns. Veterinary Parasitology 136, 283-295.

22. Fourie JJ, Crafford D, Horak IG, Stanneck D. 2012. Prophylactic treatment of flea-infested cats with an imidacloprid/flumethrin collar to forestall infection with Dipylidium caninum. Parasites \& Vectors, 5, 151.

23. Fourie JJ, Crafford D, Horak IG, Stanneck D. 2013. Prophylactic treatment of flea-infested dogs with an imidacloprid / flumethrin collar (Seresto, Bayer) to preempt infection with Dipylidium caninum. Parasitology Research, 112, 33-46.

24. García-Agudo L, García-Martos P, Rodríguez-Iglesias M. 2014. Dipylidium caninum infection in an infant: a rare case report and literature review. Chinese Journal of Schistosomiasis Control, 26, 565-567.

25. Gates MC, Nolan TJ. 2009. Endoparasite prevalence and recurrence across different age groups of dogs and cats. Veterinary Parasitology, 166, 153-158.

26. Johnson SAM, Gakuya DW, Mbuthia PG, Mande JD, Maingi N. 2015. Prevalence of gastrointestinal helminths and management practices for dogs in the Greater Accra region of Ghana. Heliyon, 1(1), e00023.

27. Kamani J, Baneth G, Gutiérrez R, Nachum-Biala Y, Salant H, Mumcuoglu KY, Harrus S. 2015. Molecular screening of Ctenocephalides felis fleas collected from stray cats in the Jerusalem District, Israel, for Bartonella spp., Rickettsia spp. and Coxiella burnetii. Veterinary Parasitology: Regional Studies and Reports, 1, 59-64.

28. Labarthe N, Serrão ML, Ferreira AMR, Almeida NKO, Guerrero J. 2004. A survey of gastrointestinal helminths in cats of the metropolitan region of Rio de Janeiro, Brazil. Veterinary Parasitology, 123, 133-139.

29. Labuschagne M, Beugnet F, Rehbein S, Guillot J, Fourie J, Crafford D. 2018. Analysis of Dipylidium caninum tapeworms from dogs and cats, or their respective fleas. Part 1. Molecular characterization of Dipylidium caninum: genetic analysis supporting two distinct species adapted to dogs and cats. Parasite, 25, 30.

30. Lahmar S, Boufana B, Ben Boubaker S, Landolsi F. 2014. Intestinal helminths of golden jackals and red foxes from Tunisia. Veterinary Parasitology, 204, 297-303.

31. Low VL, Prakash BK, Tan TK, Sofian-Azirun M, Anwar FHK, Vinnie-Siow WY, AbuBakar S. 2017. Pathogens in ectoparasites from free-ranging animals: Infection with Rickettsia asembonensis in ticks, and a potentially new species of Dipylidium in fleas and lice. Veterinary Parasitology, 245, 102-105.

32. Martínez-Moreno FJ, Hernández S, López-Cobos E, Becerra C, Acosta I, Martínez-Moreno A. 2007. Estimation of canine intestinal parasites in Córdoba (Spain) and their risk to public health. Veterinary Parasitology, 143, 7-13.

33. Mehlhorn H. 2000. Eucestoda, in Encyclopedic reference of Parasitology: Biology, Structure, Function, $3^{\text {rd }}$ Edn, Mehlhorn H, Editor. Springer: Berlin, Germany. p. 223-222.

34. Mohd Zain SN, Sahimin N, Pal P, Lewis JW. 2013. Macroparasite communities in stray cat populations from urban cities in Peninsular Malaysia. Veterinary Parasitology, 196, 469-477.

35. Moskvina TV, Zheleznova LV. 2015. A survey on endoparasites and ectoparasites in domestic dogs and cats in Vladivostok, Russia 2014. Veterinary Parasitology: Regional Studies and Reports, 1-2, 31-34.

36. Oliveira-Sequeira T, Amarante A, Ferrari T, Nunes L. 2002. Prevalence of parasites in dogs from Sao Paulo state, Brazil. Veterinary Parasitology, 103, 19-27.

37. Papazahariadou M, Founta A, Papadopoulos E, Chliounakis S, Antoniadou-Sotiriadou K, Theodorides Y. 2007. Gastrointestinal parasites of shepherd and hunting dogs in the Serres Prefecture, Northern Greece. Veterinary Parasitology, 148, 170-173.

38. Pugh RE, Moorhouse DE. 1985. Factors affecting the development of Dipylidium caninum in Ctenocephalides felis felis (Bouché, 1835). Zeitschrift für Parasitenkunde, 71, 765-775.

39. Pugh RE. 1987. Effects on the development of Dipylidium caninum and on host reaction to this parasite in the adult flea (Ctenocephalides felis felis). Parasitology Research, 73, 171-177.

40. Richards DT, Harris S, Lewis, JW. 1995. Epidemiological studies on intestinal helminth parasites of rural and urban red foxes (Vulpes vulpes) in the United Kingdom. Veterinary Parasitology, 59, 39-51.

41. Riggio F, Mannella R, Ariti G, Perrucci S. 2013. Intestinal and lung parasites in owned dogs and cats from central Italy. Veterinary Parasitology, 193, 78-84.

42. Sahin I, Köz S, Atambay M, Kayabas U, Piskin T, Unal B. 2015. A rare cause of diarrhea in a kidney transplant recipient: Dipylidium caninum. Transplantation Proceedings, 47, 2243-2244.

43. Shin JW, Liao WT. 2002. Humoral immune response to Dipylidium caninum infection of stray dogs in Taiwan. Veterinary Parasitology, 104, 351-356.

44. Soran MM, Ciopasiu RM, Ionita M, Mitrea IL. 2015. Investigation of endoparasite community of dogs and cats in 
urban areas in South-Eastern Romania: Potential risks for animal and public health. Journal of Biotechnology 208, S96.

45. Soriano SV, Pierangeli NB, Roccia I, Bergagna HFJ, Lazzarini LE, Celescinco A, Saiz MS, Kossman A, Contreras PA, Arias C, Basualdo JA. 2010. A wide diversity of zoonotic intestinal parasites infects urban and rural dogs in Neuquén, Patagonia, Argentina. Veterinary Parasitology, 167, 81-85.

46. Takeuchi-Storm N, Mejer H, Al-Sabi MNS, Olsen CS, Thamsborg SM, Enemark HL. 2015. Gastrointestinal parasites of cats in Denmark assessed by necropsy and concentration McMaster technique. Veterinary Parasitology, $214(3-4), 327-332$.

47. Traub RJ, Robertson ID, Irwin PJ, Mencke N, Thompson RCA. 2005. Canine gastrointestinal parasitic zoonoses in India. Trends in Parasitology, 21, 42-48.

48. Ziadinov I, Deplazes P, Mathis A, Mutunova B, Abdykerimov K, Nurgaziev R, Torgerson PR. 2010. Frequency distribution of Echinococcus multilocularis and other helminths of foxes in Kyrgyzstan. Veterinary Parasitology, $171,286-292$.

Cite this article as: Beugnet F, Labuschagne M, Vos Cd, Crafford D, Fourie J. 2018. Analysis of Dipylidium caninum tapeworms from dogs and cats, or their respective fleas. Parasite 25, 31

\section{(0) PARASTE}

An international open-access, peer-reviewed, online journal publishing high quality papers on all aspects of human and animal parasitology

Reviews, articles and short notes may be submitted. Fields include, but are not limited to: general, medical and veterinary parasitology; morphology, including ultrastructure; parasite systematics, including entomology, acarology, helminthology and protistology, and molecular analyses; molecular biology and biochemistry; immunology of parasitic diseases; host-parasite relationships; ecology and life history of parasites; epidemiology; therapeutics; new diagnostic tools.

All papers in Parasite are published in English. Manuscripts should have a broad interest and must not have been published or submitted elsewhere. No limit is imposed on the length of manuscripts.

Parasite (open-access) continues Parasite (print and online editions, 1994-2012) and Annales de Parasitologie Humaine et Comparée (1923-1993) and is the official journal of the Société Française de Parasitologie. 